\title{
Research on the Transition from Kindergarten Language Education to Primary School Language Education
}

\author{
Lina Zhang ${ }^{1}$ Dongqing Bail ${ }^{2}$ Han Yin ${ }^{3}$ \\ 'Teachers' College Shenyang University \\ Shenyang, China \\ 'Teachers' College Shenyang University \\ Shenyang, China \\ ${ }^{3}$ No.1 Wanghua Kindergarten affiliated to Education Bureau Dadong District \\ Shenyang, China
}

\begin{abstract}
Keywords: transition from kindergarten to primary school; language education; strategies
\end{abstract}
\begin{abstract}
This paper analyzes the current situation and existing problems of the language education in the transition from kindergarten to primary school and proposes corresponding strategies by literature, observation, interview and other methods. Based on the perspectives of lifelong education and continuous education, with rich literature and a large number of factual evidence, supplemented by the actual data obtained from the survey interviews, this paper analyzes the language education problems in the transition from kindergarten to primary school, thereby proposing targeted suggestions on how to realize the language education in the transition from kindergarten to primary school.
\end{abstract}

\section{Definition of related concepts}

\subsection{Language}

Language is a symbolic system that takes phonetics as the material shell, semantics as the meaning content, and combines phonetics and meaning with lexical building materials and grammatical organization rules to express human thought. Language is a social phenomenon, which is the most important communication tool for human beings. It is a tool for thinking and transmitting information, and a carrier for human beings to preserve their achievements.

\subsection{Language education}

Language education refers to the teaching behavior and learning behavior of any language, including text form, phonetics, vocabulary, grammar, listening, conversation, reading and writing.

The language education of children is mainly to provide the language environment of Putonghua, to train children to speak Mandarin correctly, to create a free and relaxed language communication environment, so as to cultivate the habits of children's language communication and improve the language communication ability of children. At the same time, language education guides and enhances children's ability to listen and appreciate children's literature, and stimulates children's interest in reading and writing, so as to prepare children for further study after entering school ${ }^{[1]}$.

\subsection{Transition from kindergarten to primary school}

Transition from kindergarten to primary school refers to the connection between kindergarten and primary education, which is also a major turning point for young children in the process of development. The core is how children of this age can effectively adapt to the primary school life from the way of thinking, study habits, social skills, etc., so as to achieve a smooth transition from kindergarten to primary school ${ }^{[2]}$. 


\section{The survey of the transition between kindergarten language education and primary school language education}

\subsection{Survey design}

\subsubsection{Survey purpose}

Through interviews on language education in the transition from kindergarten to primary school, this paper analyzes the current situation and existing problems of the language education in the transition from kindergarten to primary school, and proposes corresponding solutions to better promote the smooth transition of children to primary school.

\subsubsection{Survey object}

In this study, a large class teacher of a kindergarten in Dadong District of Shenyang City and a first-grade Chinese teacher of a primary school were selected as research objects.

\subsubsection{Survey content}

The content of this research survey can be divided into three parts;

The first part is an interview with the primary school Chinese teachers. The main contents include the views on the preparation of the new language before entering the school, the views on the four aspects of the ability to listen, speak, read and write, and the suggestions for the preparation of the textbook.

The second part is an interview with the kindergarten teachers, which mainly includes preparations for language education for children who are about to enter primary school, work in language education, communication with primary school teachers, and setting of related teaching materials.

The third part is the classroom observation of the kindergarten large class language activity class and the primary school Chinese class. Through classroom observation, it analyzes the differences in language teaching in the transition stage

\subsubsection{Survey methods}

This paper mainly uses the following research methods:

Interview method: through the prepared interview outline, 13 teachers in the primary school and 6 teachers in the kindergarten are interviewed in depth, and some doubts, opinions, suggestions and so on for the language education in transition from kindergarten to primary school are obtained through interviews.

Observation method: this study adopts the natural observation method in the observation method, and raises and analyzes the problem through observation and record.

\subsection{Analysis of the survey}

\subsubsection{Differences in language education goals between kindergarten and primary school}

Some interview records are as follows:

Teacher T: "Generally, I design teaching objectives based on the content of the textbook."

Teacher Y: "The child's interest is really important, but parents still want to their children learn a relatively difficult knowledge."

In interviews with teachers, it is found that most teachers design teaching objectives according to the content of language teaching; some teachers believe that the design teaching objectives should consider the requirements of parents; only a few teachers believe that language education goals should be based on children's interests.

The language education goal in the "Guidelines for the Guidance of Kindergarten Education (Trial)" stipulates that "the different moods expressed by different symbols are understood in reading"; the goal of language education in "Criteria for Compulsory Education Chinese Courses" stipulates that "the students need to know 100 Chinese characters and write 50 Chinese characters." ${ }^{[3]}$ By comparison, the goals of kindergarten and primary school language education are very different. It is recommended that kindergarten teachers and primary school teachers do a good job of communication, and take some effective methods in the teaching process to help children to successfully cross the transition from kindergarten to primary school stage. 


\subsubsection{Differences in language education content between kindergarten and primary school}

Some interview records are as follows:

Teacher L: "Because children are young and their concentration is more difficult to focus on, most of the time they take a language course in the form of a picture book."

Teacher Q: "In the process of drawing lesson, children can freely play the plot and exercise their imagination through pictures. The picture book is still a good way of education."

The primary school language education curriculum has a textbook uniformly compiled by the Ministry of Education, and the content is more focused on pinyin literacy. Therefore, it is difficult for children who are new to primary school to understand abstract pinyin and words, and thus may gradually lose interest in learning Chinese. It can be seen that the differences in language education content between kindergarten and primary school are very large.

\subsubsection{Differences in language education methods between kindergarten and primary school}

Some interview records are as follows:

Teacher X: "Although we know that game teaching can stimulate children's interest, we only use the game teaching occasionally because of the heavy learning tasks."

Classroom teaching in primary schools pays more attention to the teaching of knowledge and repeated practice. In teaching methods, teaching methods and practice methods are mainly used. "Playing through learning, learning through playing" and" teaching through lively activities " are the teaching philosophy and purpose of kindergarten. Kindergarten pays more attention to game teaching. Therefore, the differences in in language education methods between kindergarten and primary school are also very large.

2.2.4. Differences in language education teaching evaluation between kindergarten and primary school

Some interview records are as follows:

Teacher L: "It is very necessary to praise and encourage children's language in a timely manner. For example, we should give timely praise and encouragement to children who have mastered new words.

Teacher H: "Tests and examinations are the most important ways to test students' learning situation."

It is learned from interviews that most kindergarten teachers are more superficial in their evaluation of language learning. Most primary school teachers take the test scores, the mastery of pinyin literacy and the ability to understand knowledge as the main aspects of language learning evaluation. It can be seen that there are also large differences in language education teaching evaluation between kindergarten and primary school.

\section{The language education problems in the transition from kindergarten I to primary school}

\subsection{Parents' language education concept is backward, and they pay attention to knowledge and ignore ability}

As we all know, Chinese children are good at exams, and they are the most outstanding children in exams. However, Chinese children will obviously lag behind the children of the developed countries in the world when they turn their knowledge achievements into practical abilities, which is inseparable from the parents' educational philosophy. Chinese parents value how much book knowledge children have and rarely consider how much their children acquire. Therefore, parents pay more attention to how many words they learn, how many ancient poems they will recite, and rarely think about how to develop their children's language skills, such as reading ability and expression ability in language education.

\subsection{Teachers' language education is utilitarian, and they value literacy and ignore interest}

At present, most kindergarten large class teachers are eager to make children's language vocabulary reach a certain number in order to meet the goal of primary school language education. They adopt the practice of focusing on the introduction of new words to prepare for the promotion to primary 
school. However, the boring word teaching is difficult to attract children's interest in the teaching process. Interest is the premise of everything, if the child is not interested in this boring teaching method, then the teaching will get half the result with twice the effort. Therefore, cultivating interest in learning and letting children learn passively to learn actively enable educational achievements to get twice the result with half the effort

\subsection{The language education transition between kindergarten and primary school is not balanced, and the one-way transition is outstanding}

Transition from kindergarten to primary school is a very important job for kindergartens. Kindergartens can actively carry out all aspects of preparatory work for children before they enter primary school, regardless of their teaching objectives, content, methods, evaluation, and schedule. However, most primary schools do not take the initiative to contact with kindergartens, and rarely consider the physical and mental characteristics of children when they first enter school, thus creating a one-way connection.

\subsection{There is the lack of support for language education transition in the management of educational institutions}

At present, the work of language education transition from kindergarten to primary school only stays on the surface, such as the extension of class time, the reduction of games and activities. However, the content, methods, evaluation and other work of language education have not been really carried out. Therefore, language education transition from kindergarten to primary school requires the educational institutions to further plan from the perspective of management. Without the strong support of educational institutions, the work of language education transition from kindergarten to primary school is difficult to implement.

\section{The strategies for implementing the language education in transition from kindergarten to primary school}

\subsection{Emphasis on the work of parents and the consensus of parents to obtain language education in transition}

The ecological theory of human development believes that transition from kindergarten to primary school is a three-dimensional educational system. Kindergartens, primary schools, families, and society all come from this educational system, which are also mutual influence. Meanwhile, as the first teachers of the children, parents have a profound impact on all aspects of the children. Therefore, kindergarten and primary school teachers must communicate with parents in a timely manner. By inviting parents to come to the school for visits and experiences, the school helps parents to establish a correct view of education and reach an educational consensus with parents to ensure that the work of transition from kindergarten to primary school is carried out smoothly. ${ }^{[4]}$

\subsection{Strengthen language teachers' professional training of language education in the transition from kindergarten to primary school}

Children and primary school students are at different ages, thus their physical and mental development characteristics are different. Kindergarten and primary school language teachers must follow the development characteristics and laws of children at different stages so as to do a good job on the language education in the transition from kindergarten to primary school. Through the unified training of language professional kindergartens and primary school teachers, kindergarten and primary school teachers can understand each other's language education and teaching work, and they can better cooperate and communicate with each other.

Therefore, they can jointly explore the research and propose corresponding countermeasures on the problems in the in the transition from kindergarten to primary school stage. 


\subsection{Enhance the interaction between kindergarten and primary school teachers, and improve the quality of language education in transition stage}

The fundamental purpose of the transition from kindergarten to primary school is to adapt to the continuity of children development by maintaining the continuity of learning environment continuity in kindergarten and primary school. The effective interaction between kindergarten and primary school teachers is the key to maintaining the continuity of the learning environment in kindergartens and primary schools, which ensures the continuity of the relationship between teachers and students in kindergarten and primary school, the continuity of educational concepts and the continuity of curriculum teaching. Through the interaction between kindergarten and primary school teachers, it is also possible to ensure the continuity of the relationship between teachers and students in kindergarten and primary school, the educational philosophy and the continuity of curriculum teaching. Therefore, the interaction between teachers at two different stages of kindergarten and primary school should be a form of normalization. Kindergartens and primary schools should develop effective communication rules through consultation to ensure the quality of language education.

\subsection{Establish relevant management systems to ensure the effective language education transition from kindergarten to primary school.}

Although the transition from kindergarten to primary school is a hot topic in the education fields, China has not given enough attention to the young at the policy level. Compared with the kindergarten language education, the primary school is indifferent. Based on the policy level, we should first strengthen the role of primary schools language education in the transition from kindergarten to primary school. Secondly, it is necessary to gradually incorporate pre-school education into the scope of compulsory education so that two different stages of education can be organically integrated, so as to break the vacuum between early childhood education and primary education, thus ensuring the effective language education transition from kindergarten to primary school. ${ }^{[5]}$

\section{Conclusions}

Combined with interviews with kindergarten and primary language teachers and observations of language classes, this study summarizes the language education problems in the transition from kindergarten to primary school and proposes strategies for these issues:

1. It is recommended to pay attention to the work of parents and the consensus of parents to achieve language education in the transition from kindergarten to primary school.

2. It is recommended to strengthen the professional training of the kindergarten and primary school teachers' language education in the transition work.

3. It is recommended to enhance the interaction between the kindergarten and primary school teachers and improve the quality of language education in transition stage.

4. It is recommended to establish relevant management systems to ensure the effective language education transition from kindergarten to primary school.

\section{References}

[1] Cao Lu. Study on language education in the view of transition from kindergarten to primary school. [D] Xinyang Teachers' College 2016(7-12).

[2] Liu Xiaohong. Jiang Feifei. From "Language" to "Chinese"----The way to transition from kindergarten language education to primary school language education $[\mathrm{J}]<$ Good Father and Mother> 2016 Num.39

[3] [3] Qin Ni. Discussion on differences between kindergarten language education and primary school Chinese education <Teachers> 2016 Num.9 
[4] Hong Mengchun. Study on kindergarten-family cooperation in the field of transition from kindergarten to primary school. Fujian Normal University 2016 (15-32 )

[5] Wang Jiajing. Investigation into the problems of Grade 1 Chinese education in the transition from kindergarten to primary school and study on education strategies Yangzhou University 2013 (24-40). 